House was not a proper place in which to put the plaintiff, bearing in mind her antecedent history. He came to the conclusion (without wishing to express any censure on this large and well-conducted establishment) that to put the plaintiff at that time in that ward with that open door and that gas and the single nurse was not taking reasonable care of her, and she was entitled to damages, which must be reasonable, and he awarded her $€ 450$, with costs.

Solicitors.-Messrs. Edwards and Son; Messrs. Dixon and Hunt.

(Abstract from The Times' report, March 18th, 19th and 23rd, 1921.)

\title{
CORRESPONDENCE.
}

\section{Ministry of Health (Miscellaneous Provisions) Bill.}

To the Editors of the Journal of Mental Science.

SiRS,-As I understand the "Occasional Note" on the above matter in the last issue of the Fournal of Mental Science is not an official expression of opinion of the Medico-Psychological Association, it is unfortunate that the writer should claim to be voicing the views of the majority of the members of the Association. How he can say that the Ministry of Health Bill, Clause ro, would have been a retrograde step, and that it was "of doubtful efficiency as regards the incipient insane" and "decidedly reactionary as regards the certified insane" it is difficult to understand. It left untouched the treatinent of the certified insane, as the Bill was not a Lunacy Act Amendment Bill, and its clauses were to facilitate the early treatment of mental disorder.

The writer of the note seems to have been nettled by certain observations made by some members of the House of Commons during the discussion of the Bill, but although he may have just grounds for his indignation, no branch of medicine can afford to delay its advance merely because the public has not learnt to appreciate the good work that is already being done in it. It is common knowledge that much mental disorder might be prevented if the cases came for treatment at an earlier stage of their illness. Clause 10 was an honest attempt to render this early treatment possible.

It is true that it did not go as far as the medical profession would have wished. The necessity of having a letter signed by the patient before he could be admitted to an approved Home limited and greatly lessened the value of the measure. The Minister himself knew this and appreciated the force of the argument of all of us who pressed for the omission of this letter, but on the other hand he knew also that the legal members of the House would oppose the Bill unless some such protection were included, and finally we had to say that we preferred a half measure rather than none at all. In Committee, Colonel Raw's amendment, that in the event of a patient's being unable to sign the letter the nearest relative should do so, was almost carried, indicating that we might look forward to relief from this restriction at some not distant date.

Some members of the Association were disappointed that the Minister did not bring in a voluntary boarder system for county and borough asylums. Whilst thoroughly in sympathy with this provision, he stated in Committee that it could not be dealt with under the present Bill, but only by a Lunacy Act Amendment Bill.

I find that an idea has got about that the privileges under this Bill were not to be extended to mental hospitals. It is not clear how this idea originated, but I can only say that I personally have always pressed, and the principle has always been accepted, that any concession as to early treatment should be enjoyed by all mental hospitals where special provision may be made for these cases, and by all licensed houses equally with any approved home which might be included under the Act if it passed.

I am not aware of any proposal for a new public department to deal with these cases, nor would such be necessary, while with regard to the writer's comment as to the Board of Control, it is clear that the Minister intended to avail himself of their knowledge and experience, as may be seen from the statement of Colonel Wilson, speaking for the Minister in Committee: "It is proposed by the Ministry that the inspection of these institutions shall be carried out by medical officers on 
the staff of the Ministry, but it is obvious that the hands of the Ministry must be left free. In certain and very special cases it may be necessary to utilise the experience of the Board of Control, and the Minister should be left free to do so."

Unfortunately the treatment of mental disorder is a branch of medicine which more than any other is hampered by the exigencies of the law, and this has made our advancement slow. The system in the past has been too narrow and the remedy for the removal of the "stigma of lunacy" by treating voluntary and detained patients in county and borough asylums, as suggested by the writer of this note, is far from being a hopeful one when we bear in mind that registered mental hospitals and licensed houses have for thirty years been able to do this. No, the remedy lies in a far wider vision, and unless we, as an Association, can show by our policy that we have this, there is little doubt that we shall, and rightly, be superseded by those who have.

87, Harley Street, W. I ;

I am, Sirs, your obedient servant, March 16 th, 1921.

[Sir Maurice Craig is correct in his supposition that our Editorial remarks on Clause to of the Ministry of Health (Miscellaneous Provisions) Bill are not an official expression of opinion of the Medico-Psychological Association. He need be under no misapprehension regarding the writer he refers to. "Occasional Notes" are Editorial utterances for which the Editors are solely responsible. Neither is any such claim as he mentions made. The Association sent a wire to the Minister of Health definitely stating that it desired the clause to be withdrawn if its amendments were not accepted. The amendments not being found acceptable, it is obvious that the comment in the early part of paragraph I was fully justified. The attitude taken up by the Ministry on this subject as regards the mental hospitals and Board of Control is too well known to the Association to need recapitulating here. The Association will be glad to learn that as far as Sir Maurice Craig is concerned he is one with us that "any concession as to early treatment should be enjoyed by all mental hospitals, etc." Such an assurance would have been better timed when the Bill was under consideration by the Association, but it is nevertheless welcome. We venture to think that this is just the soul and centre of the Association claim, neither more nor less. We do not propose to discuss the remaining points of the letter. Members will judge for themselves as to the correctness or propriety of the Journal's remarks on this subject. We will only say that any measure under which there is the chance of excluding the great majority of practising alienists from the treatment of incipient, recent or acute cases, whether certified or not, is of doubtful efficiency, and will react unfavourably on the status of the established mental hospitals and their patients.-EDs.]

\section{OBITUARY.}

\section{Antoine RitTi.}

IT was a very little company that on January 25 th, 1920, followed to its last resting-place the body of Antoine Ritti, borne, in compliance with his request, upon the pauper's bier. His wishes that no letters of invitation should be sent out and no oration delivered were scrupulously observed, and not till afterwards did a laconic announcement he had himself drawn up appear in an evening paper. It was all very simple and business-like, characteristic of the man and everything he did. So passes from the ranks of medicine a good and faithful servant and from the roll of honorary members of our Association a distinguished name.

Born in 1844 , under the shadow of the cathedral of Strasbourg, where his uncle was bishop, and educated at the Catholic Gymnase at Colmar, founded by that same uncle, he was considered by his relatives to have a vocation for the church but when he was about twenty years old he embraced the positive philosophy of Auguste Comte, and a little later became a student of medicine. Clouds hung over his student days; he was interne at an obscure provincial asylum under fameless chiefs (Fains, 1867-70), his studies were interrupted by the FrancoPrussian war, and he was uprooted from his native Alsace by his choice of French nationality. He entered upon the practice of his profession in 1874 as a medical 